\title{
Acute Testicular Torsion in Children: A Tertiary Hospital Experience in a Developing Country
}

\section{Running title: Acute Testicular Torsion}

Chukwubuike Kevin Emeka

Pediatric Surgery Unit, Department of Surgery, Enugu State University Teaching Hospital, Enugu, Nigeria.

Corresponding to: Chukwubuike Kevin Emeka, Department of Surgery, Enugu State University Teaching Hospital, Enugu, Nigeria.

Received date: July 19, 2020: Accepted date: August 09, 2020: Published date: August 16, 2020

Citation: Chukwubuike K Emeka. (2021) Acute Testicular Torsion in Children: A Tertiary Hospital Experience in a Developing Country. Journal of Clinical Surgery and Research. 2(4) DOI: 10.31579/2768-2757/024

Copyright: @2021 Chukwubuike Kevin Emeka, This is an open-access article distributed under the terms of the Creative Commons Attribution License, which permits unrestricted use, distribution, and reproduction in any medium, provided the original author and source are credited.

\begin{abstract}
Background: Testicular torsion is a urological emergency in which there is a race against time to salvage the testis. The aim of this study was to evaluate our experience in the management of children who presented with acute testicular torsion.

Materials and Methods: This was a retrospective study of children aged 15 years and below who had surgery for acute testicular torsion between January 2013 and December 2017 at the pediatric surgery unit of a teaching hospital in Enugu, Nigeria.

Results: Sixty-four children were managed during the study period. The ages of the patients ranged from 2 months to 14 years with a median of 6 years. The right testis was mostly affected and the mean duration from the onset of symptom to presentation was 4 hours. All the patients presented with testicular pain and half of the patients had a prior history of intermittent testicular pain. Four (6.3\%) patients had a history of trauma precipitating the testicular torsion and $3(4.7 \%)$ patients had undescended testis. Detorsion and Orchidopexy was the most performed surgical procedure and wound infection was the most common post-operative complication. There was no mortality.
\end{abstract}

Conclusion: Testicular torsion is not uncommon in children and may be associated with testicular loss. The right testis is mostly involved in children. Prior history of intermittent testicular pain, trauma and undescended testis are important considerations. Prompt detorsion and orchidopexy remains the cornerstone of treatment.

Keywords: children; outcome; orchidopexy; testicular torsion

\section{Introduction}

Testicular torsion is an acute vascular event in which the spermatic cord twists on its axis impeding the blood supply to the testis. Testicular torsion may lead to ischemic injury and testicular loss [1, 2]. The reported incidence of testicular torsion is 1 in 4000 males [2]. Testicular torsion may be classified into extravaginal or intravaginal types and is typically seen in neonates and adolescents respectively [3]. The typical presentation of testicular torsion is severe unilateral scrotal pain of sudden onset which may be associated with nausea and vomiting [4]. There may also be scrotal swelling and erythema. The critical finding of testicular torsion is high riding testis due to shortening of the cord and abnormal (transverse) lie of the testis [4]. Doppler ultrasound in testicular torsion will demonstrate decreased or absent testicular blood flow. Testicular torsion is a surgical emergency and early surgical intervention is of essence to avoid testicular loss. Testicular torsion is a potentially reversible condition when diagnosed and treated early: There is the risk of irreversible testicular damage if the torsion is not treated within 6 hours [2]. The surgical treatment of testicular torsion consists of scrotal exploration, detorsion and orchidopexy. Torsion of the testicular appendage (appendix testis or appendix epididymis) is differential diagnosis of testicular torsion and surgical treatment is not required. Differentiating testicular torsion from torsion of testicular appendage is difficult; however, the pain in the latter is gradual in onset and less intense [5].

There are several studies on testicular torsion in adult. However, there is paucity of data on pediatric testicular torsion in the West African sub region. The aim of this study was to evaluate our experience in the management of children who presented with acute testicular torsion.

\section{Materials and Methods}

This was a retrospective study of children aged 15 years and below who had surgery for acute testicular torsion between January 2013 and 
December 2017 at the pediatric surgery unit of Enugu State University Teaching Hospital (ESUTH) Enugu, Nigeria. For the purposes of this study, only confirmed cases of testicular torsion at surgery were included. Cases of torsion of testicular appendage and epididymorchitis were excluded. Patients with incomplete medical records and those older than 15 years of age were also excluded from the study. ESUTH is a tertiary hospital located in Enugu, South East Nigeria. The hospital serves the whole of Enugu State, which according to the 2016 estimates of the National Population Commission and Nigerian National Bureau of Statistics, has a population of about 4 million people and a population density of $616.0 / \mathrm{km}^{2}$. The hospital also receives referrals from its neighboring states. Information was extracted from the case notes, operation notes, operation register, and admission-discharge records. The information extracted included age, presenting symptoms, prior history of testicular pain in the past, any predisposing/precipitating factors, duration of symptoms before presentation, interval between presentation and treatment, intra-operative finding (viable/non-viable testis), operative procedure performed, complications of surgery, duration of hospital stay and outcome of treatment.

\section{Protocol for scrotal exploration, detorsion and orchidopexy}

Under general anesthesia, access was through a midline vertical incision via the median scrotal raphe. Both testes were detorsed in the following manner: Right testis in anticlockwise direction and left testis in clockwise direction. Each testis was fixed at 3 points: laterally, lower and medially to prevent further torsion an avoiding the epididymis using monofilament delayed absorbable sutures. The wound was closed in layers and dressing applied.

\section{Results}

\section{Patients' demographics}

A total of 67 children were treated for acute testicular torsion during the study period but only 64 patients had complete records and formed the basis of this report. The patients' demographics are shown in Table 1.

\begin{tabular}{|l|l|}
\hline Median age Side of testicular torsion & $\begin{array}{l}\text { 6 years (range: 2 months - 14 } \\
\text { years) }\end{array}$ \\
\hline Right testis & $30(46.9 \%)$ \\
\hline Left testis & $26(40.6 \%)$ \\
\hline Bilateral & $8(12.5 \%)$ \\
\hline $\begin{array}{l}\text { Mean duration of symptoms before } \\
\text { presentation }\end{array}$ & 4 hours (range: 1-24 hours) \\
\hline $\begin{array}{l}\text { Mean interval between presentation and } \\
\text { treatment }\end{array}$ & 3 hours (range: 2-24 hours) \\
\hline Mean duration of hospital stay & 3 days (range: 1-7 days) \\
\hline
\end{tabular}

Table 1: Demographic profile of the patients $(n=64)$

\section{Presenting clinical features}

All the patients (100\%) presented with pain in the involved testis. Vomiting was present in $38(59.4 \%)$ patients and scrotal swelling in 32 $(50 \%)$ patients. High riding testis was observed in $19(29.7 \%)$ patients while $18(28.1 \%)$ patients had abnormal (transverse) lie of the testis.

\section{Prior history of similar symptoms}

Thirty-one $(48.4 \%)$ patients had a previous history of intermittent testicular pain of mild intensity.

\section{Precipitating/predisposing factors}

Four $(6.3 \%)$ patients had a history of trauma (kick to the testis and bicycle riding) preceding the testicular torsion. Three (4.7\%) patients had undescended testis and $1(1.6 \%)$ patient complained that the scrotal pain starts when the weather is very cold (during rainy season).

\section{Intra-operative finding and treatment offered}

Findings at surgery and operative procedure performed are shown in Table 2 .

\begin{tabular}{|l|l|l|}
\hline $\begin{array}{l}\text { Intra-operative } \\
\text { finding }\end{array}$ & Operative procedure & $\begin{array}{l}\text { Number } \\
(\boldsymbol{\%})\end{array}$ \\
\hline Viable testis & $\begin{array}{l}\text { Detorsion and } \\
\text { Orchidopexy }\end{array}$ & $61(95.3)$ \\
\hline Non-viable testis & Orchidectomy & $3(4.7)$ \\
\hline
\end{tabular}

Table 2: Intra-operative finding and treatment offered

\section{Complications and outcome of treatment}

Surgical site infection was recorded in $9(14.1 \%)$ patients and stitch sinus occurred in $3(4.7 \%)$ patients. Five $(7.8 \%)$ patients developed testicular atrophy. There was no case of recurrent torsion and no mortality.

\section{Discussion}

Testicular torsion is a challenging and time-sensitive diagnosis that is encountered frequently in daily medical practice. Outcome of testicular torsion depends on the duration of the torsion and the degree of the twist [6]. Every effort should be targeted at bringing the patient to the operating room as quickly as possible within the limits of surgical and anesthetic safety. Time should not be wasted chasing investigations. Four to 8 hours window from the onset of symptoms to surgery is needed in order to save a torsed testis [7]. Delays in the treatment of testicular torsion result in higher chances of needing an orchidectomy as well as the potential chances of impaired infertility [7].

In the present study, the median age of our patients is consistent with the reports of other authors $[8,9]$. However, one study from Iran reported a mean age of 28 months [10]. The average age of children presenting with testicular torsion may depend on the predominant type of testicular torsion (extravaginal/intravaginal). For instance, neonates have extravaginal testicular torsion while older children have intravaginal torsion. Testicular torsion was more common on the right testis in our patients. This is at variance to the report of other series on testicular torsion $[11,12]$. The exact reason for the left sided predominance of testicular torsion is not known. However, Mukendi et al reported that leftsided testicular torsion is more frequent in those younger than 16 years while right-sided torsion is more frequent in those aged 16 years and 
above [12]. The delayed presentation of our patients is evident in the mean 4 hours period before presentation. Wang et al also reported a mean period of 4 hours, between the onset of symptoms and presentation to the hospital, for the patients whose testes were salvaged and 37 hours for patients whose testes could not be salvaged [13]. The optimal time frame is less than 6 hours after onset of symptoms [2]. Howe et al reported that the time of presentation is the most important factor in determining salvageability of the testis in testicular torsion [6]. The time interval to treatment is quite important because testicular salvage rates are $90 \%$ to $100 \%$ if treatment is performed within 6 hours of onset of symptom; $50 \%$ for symptom duration of up to 12 hours and $10 \%$ for symptom duration of up to 24 hours [14]. The length of hospitalization of our patients is in line with the report of Caldamone et al [15]. Howbeit, Obi et al reported that their patients were discharged home within 24 hours following orchidopexy for testicular torsion [16]. The difference in the ages of the patients may determine the duration of hospital stay. Older children are likely to be discharged earlier than younger children.

Testicular pain is the most common and a consistent complaint in patients with testicular torsion. This was also our finding in the present report. However, Wang and Mo reported a series of children with testicular torsion who presented with abdominal pain, without testicular pain [13]. Other non-specific symptoms of testicular torsion may include nausea, vomiting and urinary symptoms [8]. These non-specific symptoms may lead to delays in diagnosis and treatment with increased incidence of testicular loss [13].

Patients with intermittent testicular torsion may present with prior history of testicular pain of mild intensity before the definitive torsion occurs. This intermittent torsion is due to instant torsion and spontaneous detorsion of the spermatic cord [17].

The roles of trauma, undescended testis and testicular torsion have been discussed by some researchers [18, 19]. Infact, Testicular torsion was first described by Louis Delasiauve in 1840 which occurred in a 15 -year old boy with undescended testis [20]. Gomes reported the association between cold weather and testicular torsion, even in the tropics [21].

Majority of our patients had viable testes and underwent detorsion and orchidopexy. This is comparable to the report of other authors $[6,10]$. But in a setting of late presentation and non-viable testis, orchidectomy remains the only option.

Wound infection may occur following surgery for testicular torsion. Wound infection was the most common complication recorded in the index study. A study from Jos, Nigeria also reported wound infection as a complication following surgery for testicular torsion [22]. However, a series from south east Nigeria reported no complications [16]. About onetenth of our patients developed testicular atrophy similar to the report of Ugwu et al [22]. Howe et al reported a testicular atrophy rate of $25 \%$ in patients who underwent orchidopexy [6]. Damage to the testicular vasculature may have caused the atrophy. No mortality was recorded in the present study similar to other series on testicular torsion [22].

\section{References}

1. Bowlin PR. Gatti JM, Murphy P. Pediatric Testicular Torsion. Surgical Clinics of North America. 2017; 97(1): 161-172.

2. Ringdahl E, Teague L. Testicular Torsion. Am Fam Physician. 2006: 74(10): 1738-1743.
3. Favorito LA, Cavalcante AG, Costa WS. Anatomic aspects of epididymis and tunica vaginalis in patients with testicular torsion. International Braz J Urol. 2004; 30(5): 420-424

4. Marcozzi D, Suner S. The nontraumatic, acute scrotum. Emerg Med Clin North Am. 2001; 19(3): 547-568.

5. Burgher SW. Acute scrotal pain. Emerg Med Clin North Am. 1998; 16(4): 781-809.

6. Howe AS, Vasudevan V, Kongnyuy M, Rychik K, Thomas LA, Matuskova $\mathrm{M}$ et al. Degree of twisting and duration of symptoms are prognostic factors of testis salvage during episodes of testicular torsion. Transl Androl Urol. 2017; 6(6): 1159-1166.

7. Mansbach JM, Forbes P, Peters C. Testicular torsion and risk factors for orchiectomy. Arch Pediatr Adolesc Med. 2005; 159(12): 1167-1171.

8. Guo X, Sun L, Lei W, Li S, Hui G. Management of testicular torsion $<360^{\circ}$ in children: a single-center, retrospective study. Journal of international Medical Research. 2020.

9. Sauvat F, Hennequin S, Ait Ali Slimane M, Gauthier F. Age for testicular torsion? Arch Pediatr. 2002; 9(12): 1226-1229.

10. Rouzrokh M, Mirshemirani A, Khaleghnejad-Tabari A Outcome of Second Look Exploration in Testicular Torsion of Children. Iran J Pediatr. 2015; 25(4): 528.

11. Marulaiah M, Gilhotra A, Moore L, Boucaut H, Goh DW. (2010) Testicular and paratesticular pathology in children: a 12year histopathological review. World J Surg. 34(5): 969-974.

12. Mukendi AM, Kruger D, Haffejee M. Characteristics and management of testicular torsion in patients admitted to the Urology Department at Chris Hani Baragwanath Academic Hospital. Afr J Urol. 2020; 26; 34.

13. Wang F, Mo Z. Clinical evaluation of testicular torsion presenting with acute abdominal pain in young males. Asian $\mathrm{J}$ Urol. 2019; 6(4): 368-372.

14. Kapoor S. Testicular torsion: a race against time. Int J Clin Pract. 2008; 62(5): 821-827.

15. Caldamone AA, Rabinowitz R. Outpatient Orchidopexy. The Journal of Urology. 1982; 127(2): 286-288.

16. Obi AO. Intermittent testicular torsion. Niger J Clin Pract. 2017; 20: 1273-1276.

17. Johnson BI, Wiener JS. Intermittent testicular torsion. BJU Int. 2005; 95(7): 933-934.

18. DaJusta DJ, Granberg CF, Villanueva C, Baker LA. Contemporary review of testicular torsion: new concepts, emerging technologies and potential therapeutics. J Pediatr Urol. 2013; 9(6 Pt A): 723-730.

19. Naouar S, Braiek S, El Kamel R. Testicular torsion in undescended testis: A persistent challenge. Asian J Urol. 2017; 4(2): 111-115.

20. Zilberman D, Inbar Y, Heyman Z, Shinhar D, Bilik R, Avigad I et al. Torsion of the crytorchid testis-can it be salvaged? J Urol. 2006; 175(6): 2287-2289.

21. Gomes D, Vidal R, Foeppel B, Faria D, Saito M. Cold weather is a predisposing factor for testicular torsion in a tropical country. Sao Paulo Med J. 2015; 133(3): 187-190

22. Ugwu BT, Dakum NK, Yiltok SJ, Mbah N, Legbo JN, Uba AF et al. Testicular torsion on the Jos Plateau. West Afr J Med. 2003; 22(2): 120-123. 